\title{
First record of the family Rotundabaloghiidae Kontschán, 2010 in Chile with the description of Rotundabaloghia (Circobaloghia) chilensis sp. nov. (Acari: Mesostigmata)
}

Jenő Kontschán (i)

Plant Protection Institute, Centre for Agricultural Research, ELKH, H-1525 Budapest, P.O. Box 102, Hungary

e-mail: kontschan.jeno@atk.hu

Received: 10 December 2021

Accepted: 10 January 2022

Available online: 27 January 2022

ASBTRACT: Rotundabaloghia (Circobaloghia) chilensis sp. nov. is described based on one female specimen collected from soil in Osorno Coastal Range, Chile. The new species differs from the other species from the subgenus Circobaloghia in the shape of peritremes, the shape and length of the ventral and dorsal setae. This is the first record of this family in Chile and also the southernmost occurrence of the family.

Keywords: Mite, taxonomy, new species, South-America.

Zoobank: http://zoobank.org/304AA9D3-0846-4435-8891-F4637CF89E87

\section{INTRODUCTION}

The subgenus Circobaloghia Kontschán, 2010 is a widely distributed pan-tropical mite group within the family Rotundabaloghiidae Kontschán, 2010. The members of this subgenus occur in the Neotropical, Afrotropical and Oriental realms (Kontschán, 2010). Contrary with the subgenus Rotundabaloghia Hirschmann, 1975, these species is well characterized by absence of the three or four pairs of short and needle-like setae in rows $j-J$ on dorsal body among the lot of uniform setae. After monographic work of Kontschán (2010), only one rotundabaloghiid was described from the Neotropical realm, from Peru (Błoszyk et al., 2019). With this new species the 80 rotundabaloghiid mite species is known from this region (from south Mexico to southern part of Brazil).

During my one of last visit to Natural History Museum of Geneva (Switzerland), a few soil samples from Chile were investigated. One of the samples contained one specimen of rotundabaloghiid mites, described herein as a first species from this family from Chile.

\section{MATERIALS AND METHODS}

The rotundabaloghiid mite specimen examined were cleared in lactic acid for a week and afterwards, the specimens were investigated on half-covered deep slides with a Leica 1000 microscope. Drawings were made with the aid of a drawing tube on a Leica 1000 microscope. The specimen is stored in $75 \%$ ethanol and deposited in the Natural History Museum in Geneva. Abbreviations: $v=$ ventral setae, $s t=$ sternal setae, $a d=$ adanal setae, $p=$ pores, $l f=$ lyriform fissures, e = epistome. All measurements and the scale bars of the figures are given in micrometres $(\mu \mathrm{m})$.

\section{RESULTS}

Taxonomy
Rotundabaloghia (Circobaloghia) chilensis sp. nov.

(http://zoobank.org/NomenclaturalActs/8338d1235840-445d-9ccc-91e9b83f61c6)

(Figures 1-7).

Diagnosis. Surface of dorsal shield smooth, dorsal setae short and smooth. All ventral setae short, smooth and needle-like, setae st 1 and st3 shorter st3 and st4. Peritremes question mark-shaped. Longitudinal groove between posterior end of pedofossae IV and posterior margin of ventral shield present.

Material examined. Holotype. female. Chili-84/8. Chile, Osorno Coastal Range, Pucatrihue; II. 1988; leg. L.E. Pena.

\section{Description}

Female $(n=1)$.

Description. Length of idiosoma 270, width 240. Shape circular, posterior margin rounded, color yellowish brown.

Dorsal idiosoma (Fig. 1). Marginal and dorsal shields fused. Majority of dorsal setae basally curved, smooth and ca 16-20 long. Three pairs of lyriform fissures situated on posterior-central area of dorsal shield. Surface of dorsal shield without sculptural pattern.

Ventral idiosoma (Fig. 2). Surface of sternal shield smooth. All sternal setae smooth and needle-like, st1 and st2 short (ca 4-5), st3 and st4 long (ca 7-9). Setae st1 situated close to anterior margin of sternal shield, st2 at level of central area of coxae II, st3 at level of central area of coxae III, st4 at level of anterior margin of coxae IV. All ventral setae short (ca 6-8 long), smooth and needle-like. Setae v2 situated near basal edges of genital shield, $v 7$ and $v 8$ situated at level of setae $a d$. Setae $v 6$ situated close to $v 2$. Setae $a d$ placed lateral to anal opening, at level of its anterior margin. Ventral shield without sculptural pattern. One pair of lyriform fissures situated close to setae $v 2$, other one pair 
close to $v 7$. Two pairs of pores placed close to setae $v 2$ and on pair close to setae $a d$. Peritremes short, poststigmatid part absent, prestigmatid part question markshaped. Stigmata situated between coxae II and III. Genital shield wide, linguliform (100 long and 56 wide at level of st4), without apical process and without sculptural pattern, only some longitudinal shallow grows visible on posterior part. Pedofossae deep, their surface smooth, separate furrows for tarsi IV present. Longitudinal groove between posterior end of pedofossae IV and posterior margin of ventral shield present.
Base of tritosternum narrow, vase-like, tritosternal laciniae smooth, subdivided into three smooth branches in its distal half (Fig. 3).

Gnathosoma (Fig. 3). Corniculi horn-like, internal malae smooth and as long as corniculi. All hypostomal setae smooth and needle-like, $h 1$ long (ca 11-12), $h 2, h 3$ and $h 4$ shorter (ca 5-6). Epistome apically serrate. Palp with smooth and needle-like setae. Chelicerae not visible.

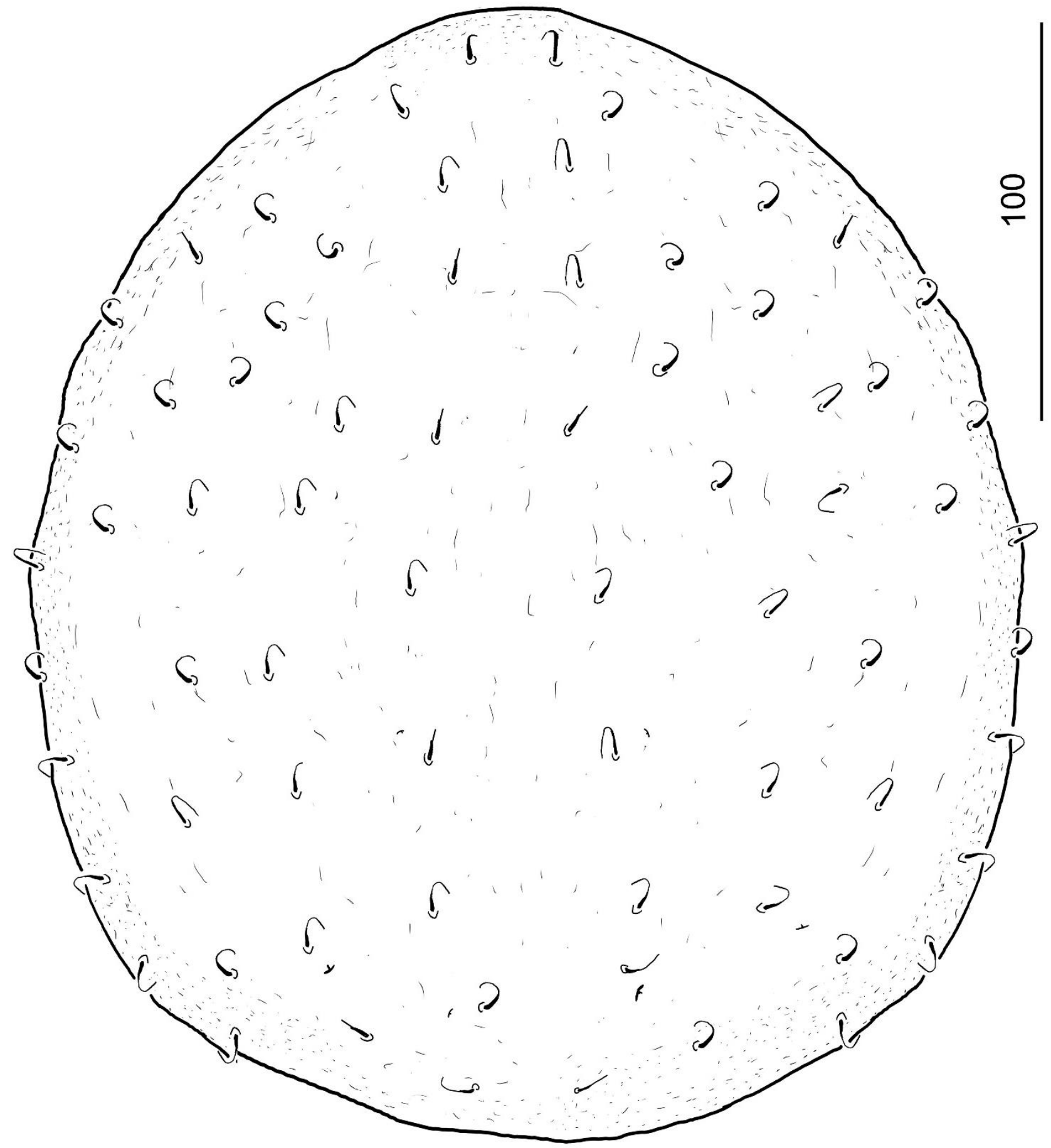

Figure 1. Dorsal view of Rotundabaloghia (Circobaloghia) chilensis sp. nov. female, holotype. 


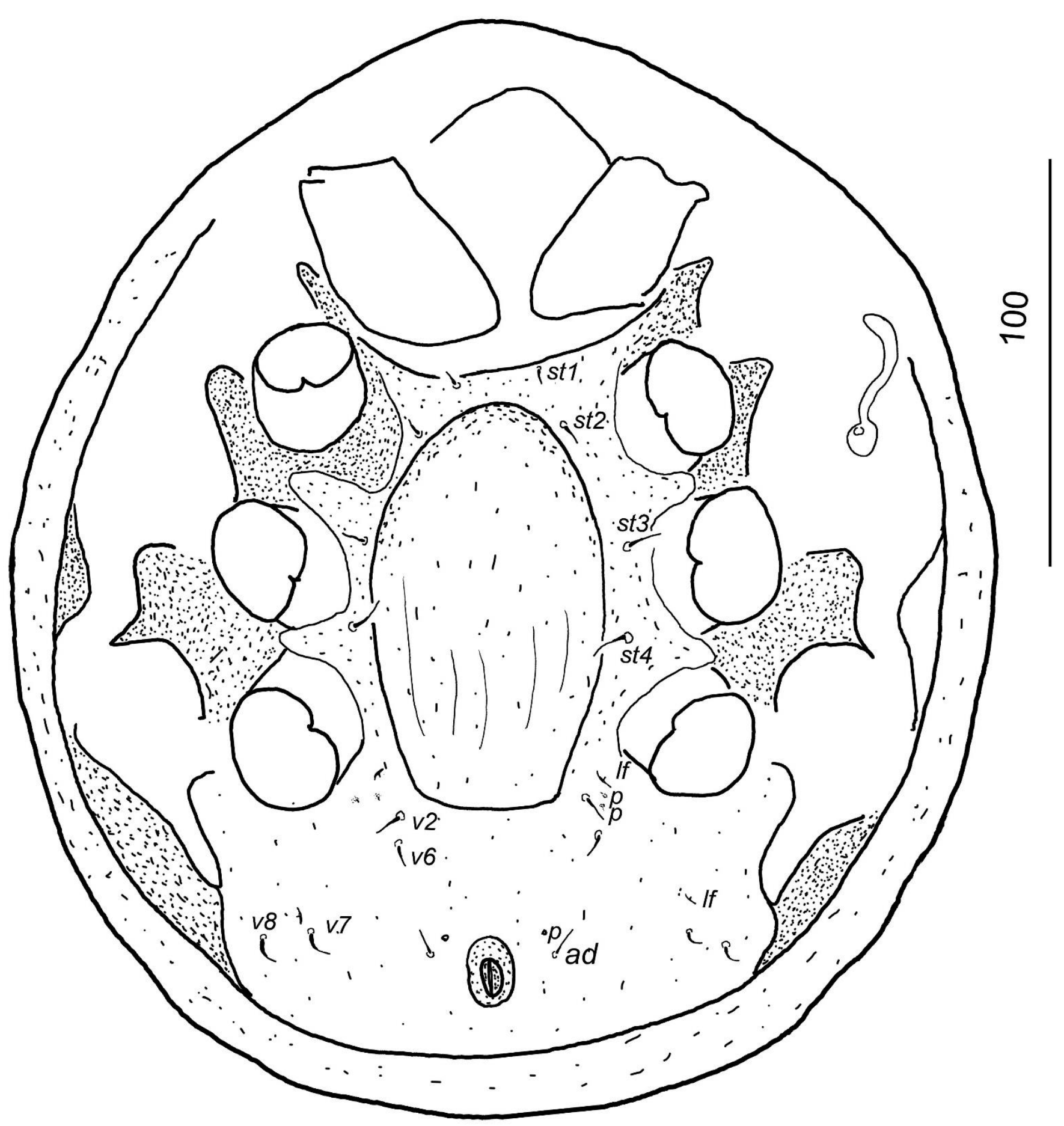

Figure 2. Ventral view of Rotundabaloghia (Circobaloghia) chilensis sp. nov. female, holotype.

Legs (Figs 4-7). All legs with smooth and needle-like setae, the claws on first leg present, but smaller than others. All femora bearing flap-like ventral processes. Leg I 140-142, leg II 108-109, leg III 100-101, leg IV 145-147.

Male and immature stages. Unknown.

Etymology. The name of the new species refers to the country where the new species was collected.
Remark. The new species has a unique character combination (short and smooth dorsal setae, short and smooth setae on ventral idiosoma, smooth surface of dorsal and ventral parts of idiosoma and the shape of peritremes, the longitudinal groove between posterior end of pedofossae IV and posterior margin of ventral shield present) which is not observable on other known rotundabaloghiid mites. 

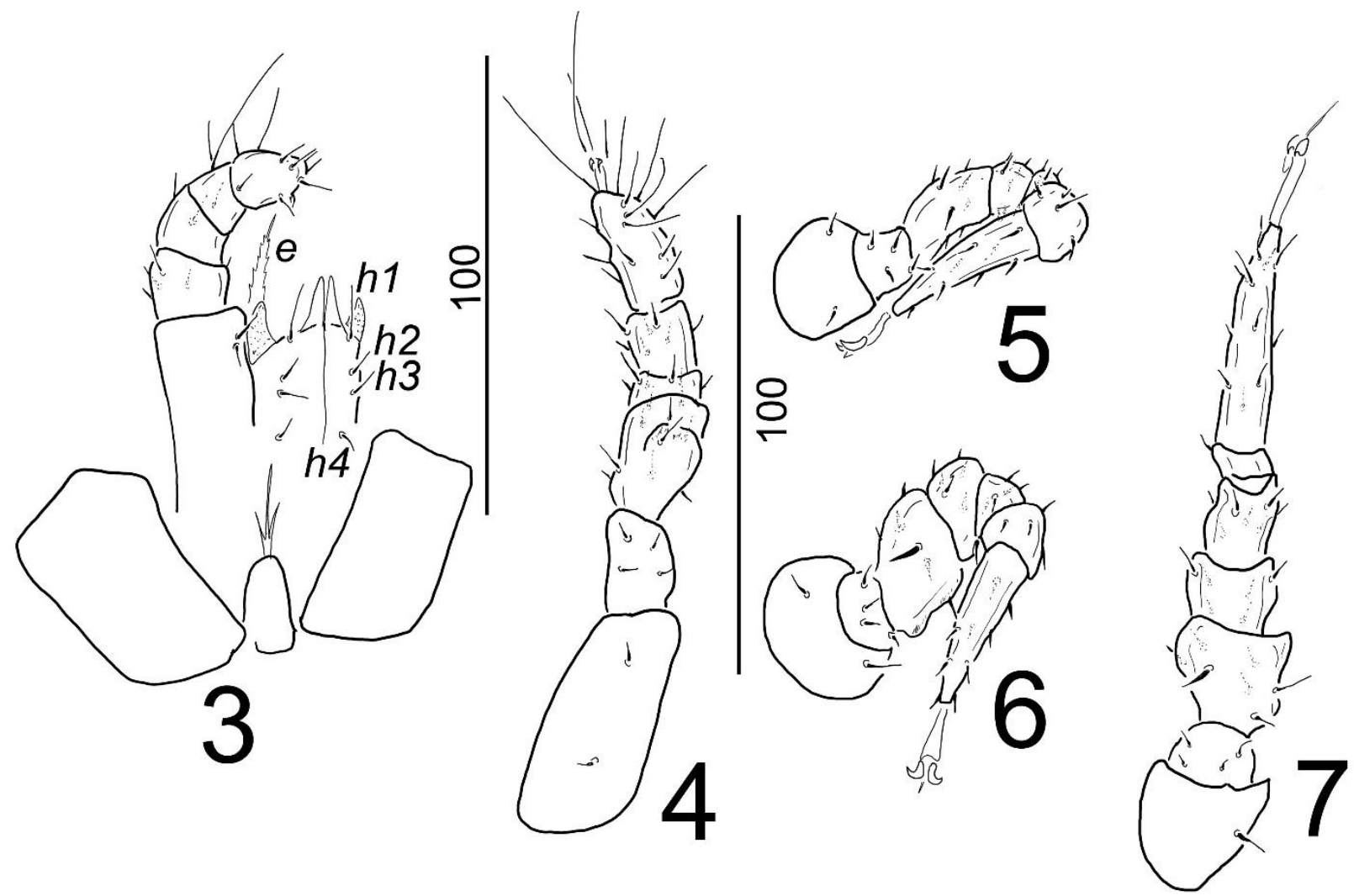

Figures 3-7. Rotundabaloghia (Circobaloghia) chilensis sp. nov. female, holotype. 3. Ventral view of gnathosoma, palp, tritosternum, epistome (e) and coxae I, 4. Leg I. in ventral view, 5. Leg II in ventral view, 6. Leg III in ventral view, 7. Leg IV in ventral view.

\section{DISCUSSION}

The new species is described based on only a single specimen. The new species differs several characters from the congeners that confirming that this is a unique, separated, and easy to recognize species, on other hand, this type locality is lying very far from other localities (Fig. 8). Our knowledge about biodiversity would be very poor without the information about the very rare species, especially in tropical areas. Therefore, the description of the new species based on a single specimen is very important and it seems to be a bad way to not describe these ones. On the other hand, the description of a new species based on a single specimen is not a rare phenomenon in the invertebrate taxonomy, where $30 \%$ of the known species is described based on a single type specimen (see Lim et al., 2012). Naturally, several researchers reject this practice (see Dayrat, 2005), because the intraspecific variability is not observable in this case.

\section{Statement of ethics approval}

Not applicable.

\section{Funding}

This study was not supported or not studied granting by any foundation.

\section{Conflict of interest}

No potential conflict of interest was reported by the author.

\section{Acknowledgements}

I am very grateful to Dr. Peter Schwendinger (Natural History Museum of Geneva, Switzerland) for his kind hospitality during my stay in Geneva.

\section{REFERENCES}

Błoszyk, J., Friedrich, S. and Skoracki, M. 2019. Rotundabaloghia dillerae, a new species of soil mite (Parasitiformes: Uropodina: Rotundabaloghiidae) from Peru. International Journal of Acarology, 46 (1): 48-51. doi: 10.1080/01647954.2019.1703810

Dayrat, B. 2005. Towards integrative taxonomy. Biological Journal of Linnean Society, 85 (3): 407-415. doi: 10.1111/j.1095-8312.2005.00503.x

Kontschán, J. 2010. Rotundabaloghiid mites of the world (Acari: Mesostigmata: Uropodina). Ad Librum Kiadó, Budapest, Hungary, 116 pp.

Lim, G.W., Blake, M. and Meier, R. 2012. Determining species boundaries in a world full of rarity: singletons, species delimitation methods. Systematic Biology, 61 (1): $165-169$.

doi: $10.1093 /$ sysbio/syr030 


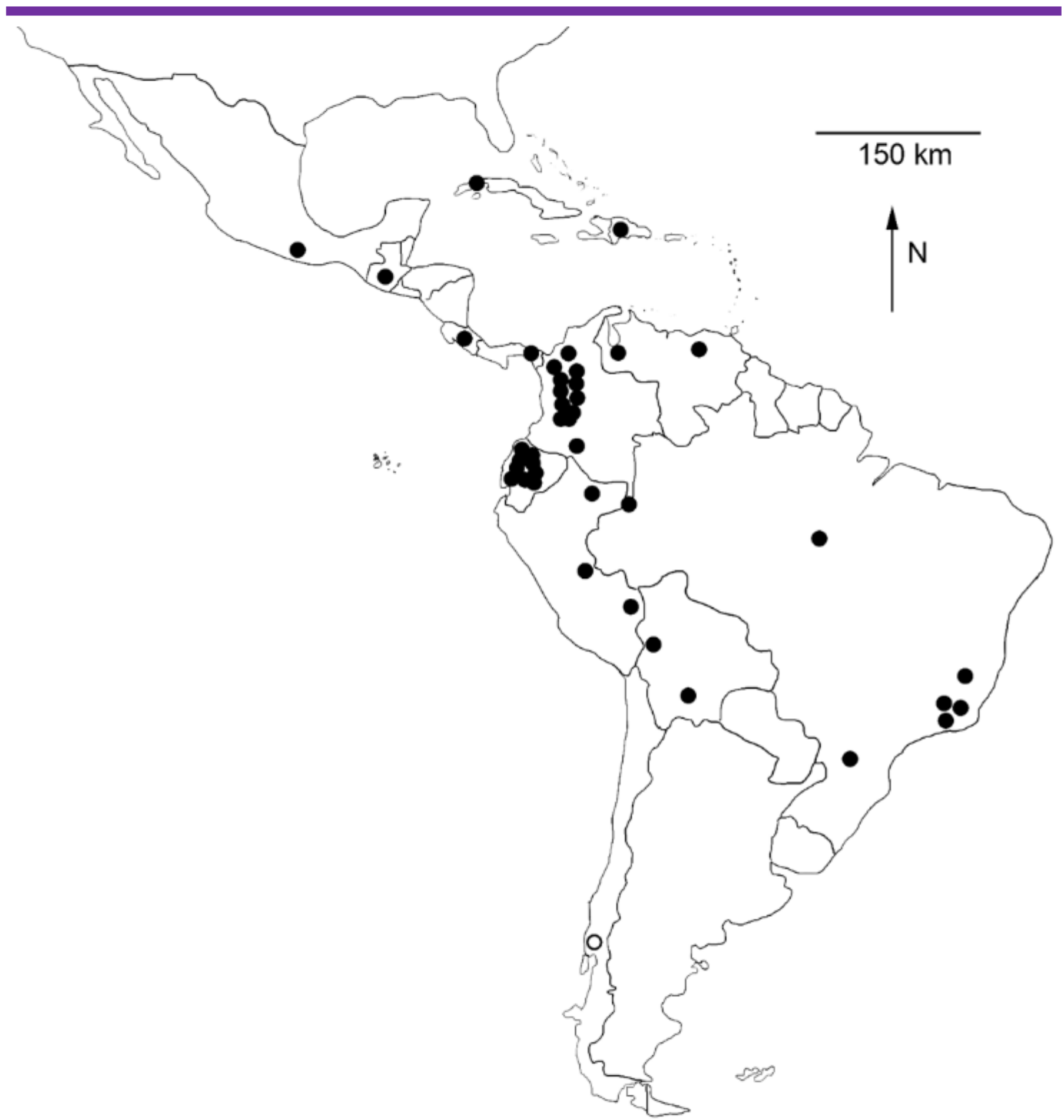

Figure 8. Occurrences of rotundabaloghiid mites in Neotropical realm (full circles: known species, empty circle: new species). 